\title{
BMJ Open Hepatotoxicity of isotretinoin in patients with acne and Gilbert's syndrome: a comparative study
}

\author{
Pablo Fernández-Crehuet, ${ }^{1}$ José Luis Fernández-Crehuet, ${ }^{1}$ \\ Mohamed Farouk Allam, ${ }^{2}$ Rafael Fernández-Crehuet Navajas ${ }^{2}$
}

To cite: Fernández-Crehuet $P$, Fernández-Crehuet JL, Allam MF, et al. Hepatotoxicity of isotretinoin in patients with acne and Gilbert's syndrome: a comparative study. BMJ Open 2014;4:e004441. doi:10.1136/bmjopen-2013004441

- Prepublication history for this paper is available online. To view these files please visit the journal online (http://dx.doi.org/10.1136/ bmjopen-2013-004441).

Received 13 November 2013 Revised 27 February 2014 Accepted 28 February 2014

CrossMark

${ }^{1}$ Dermatology Unit, Alto Guadalquivir Hospital, Andújar, Jaén, Spain ${ }^{2}$ Department of Preventive Medicine and Public Health, University of Cordoba, Cordoba, Spain

Correspondence to Dr Mohamed Farouk Allam; fm2faahm@uco.es

\section{ABSTRACT}

Objectives: The objective of our follow-up study is to evaluate liver function tests (LFTs) and lipid profiles in patients with Gilbert's syndrome treated with isotretinoin because of severe acne.

Setting: Dermatology outpatient clinics of three regional hospitals of Jaén (Spain).

Participants: Over 4 years, we included all patients diagnosed with severe acne. Only 37 patients were identified, of which 11 had Gilbert's syndrome.

Interventions: All patients were treated with isotretinoin and followed-up in our outpatient clinics after 10 and 20 weeks. Patients were subjected to an interview questionnaire which included data on age, gender, complete blood count, coagulation profile, fasting blood glucose, LFTs and lipid profiles. Data and results of patients with severe acne and Gilbert's syndrome were compared with those of 26 patients with only severe acne (control group).

Primary outcome: Blood analyses were repeated in the follow-up visits.

Results: In patients with Gilbert's syndrome, bilirubin levels showed substantial decrease over the 20-week follow-up, with more decrease after 10 weeks. None of the control group patients had significant increase in total bilirubin levels after 10 and 20 weeks of followup. Liver enzymes were maintained within normal levels in both groups. Both study groups did not show significant pathological increase in lipid profile levels. LDL levels were increased in the two study groups, but this increase was less substantial in patients with Gilbert's syndrome.

Conclusions: Our preliminary results suggest that oral isotretinoin could be an effective, safe treatment for patients with Gilbert's syndrome, and may lower bilirubin levels in the first 10 weeks of treatment. Limitations of the study include the small numbers of participants and the fact that it is restricted to one region of Spain.

\section{INTRODUCTION}

The use of isotretinoin for the treatment of severe acne has been widely known over the past 30 years. Many adverse reactions to

\section{Strengths and limitations of this study}

- All patients with severe acne who attended the dermatology outpatient clinics over 4 years were eligible to be included in our study.

- Limitations of the study include the small numbers of participants and the fact that it is restricted to one region of Spain.

iostretinoin have been reported. Several studies have shown that hepatotoxicity could occur in about $10 \%$ and hyperlipidaemia in $20-45 \%$ of the patients. ${ }^{1-3}$

Gilbert's syndrome is a benign and inherited state characterised by intermittent unconjugated hyperbilirubinaemia with accompanying jaundice in the absence of haemolysis or underlying liver disease. ${ }^{4}$ Previous studies have shown that Gilbert's syndrome affects 5-7\% of the population, mainly postpubertal male patients. $^{45}$

In patients with hepatic dysfunction, like Gilbert's syndrome, we would expect an increased sensitivity to isotretinoin that is metabolised by hepatic oxidation and biliary excretion. $^{6} 7$

The objective of our follow-up study is to evaluate liver function tests (LFTs) and lipid profiles in patients with Gilbert's syndrome treated with isotretinoin because of severe acne.

\section{METHODOLOGY}

All patients with severe acne who attended the dermatology outpatient clinics of the three regional hospitals of Andújar, Alcala la Real and Alcaudete (Jaén, Spain) over 4 years were eligible to be included in our study. Owing to the location of these three regional hospitals in the centre of Andalusia, they serve over one million persons. The study was approved by the Ethical Committee of Alto Guadalquivir Hospital (Andújar, Spain). 
Only patients with severe acne and treated with isotretinoin from 1 September 2008 to 31 August 2012 were included consecutively in the study.

Severe acne was diagnosed according to the European evidence-based (S3) guidelines for the treatment of acne. $^{8}$

Inclusion criteria were age between 14 and 20 years old, severe acne, treatment with oral isotretinoin $(0.5-0.8 \mathrm{mg} / \mathrm{kg})$ and normal LFTs and lipid profiles.

Meanwhile, exclusion criteria were contradictions for isotretinoin, concomitant use before or during the study of other treatment inducer of cytochrome P450, alcohol consumption, significant change in weight $(>10 \%)$ and suspension of the treatment.

We identified 37 patients with severe acne during the study period, of which 11 had Gilbert's syndrome.

All patients were informed about the aim of the study and signed an informed consent.

Patients were subjected to an interview questionnaire which included data on age, gender, complete blood count, coagulation profile, fasting blood glucose, liver function tests and lipid profiles. All questionnaire data were collected by the first author (PFCS) in the dermatology outpatient clinics of the three regional hospitals of Andújar, Alcala la Real and Alcaudete and the blood tests were performed at the laboratories of the same hospitals.

Basal levels of bilirubin in patients with Gilbert's syndrome were measured on three consecutive mornings. Of the three measures, the mean basal level was calculated. Fasting levels of bilirubin in patients with Gilbert's syndrome were $>1.1 \mathrm{mg} / \mathrm{dL}$.

All patients were followed up in our outpatient clinics after 10 and 20 weeks. Blood analyses were repeated in the follow-up visits. All participants were followed-up over 20 weeks with no lost follow-up.

Data and results of patients with severe acne and Gilbert's syndrome were compared with those of the 26 patients with only severe acne (control group).
No adverse effects of isotretinoin treatment were noted and in all patients the acne was in complete remission at the last follow-up visit.

\section{Statistical methods}

First, the following descriptive analysis was performed: frequency, per cent, mean, SD. Comparisons between patients with Gilbert's syndrome and control patients were performed using Mann-Whitney test for continuous variables and Pearson's $\chi^{2}$ test for categorical variables. Comparisons of LFTs and lipid profile levels over the follow-up period were performed using Friedman test. Level of significance was set at $\mathrm{p}<0.05$. All data variables were encoded and computerised. Data entry and statistical analysis were performed using the Statistical Package for Social Science (SPSS) V.15.0 (SPSS Inc, Chicago, Illinois, USA).

\section{RESULTS}

Our follow-up study included 37 patients with severe acne; 11 patients with Gilbert's syndrome and 26 control patients. No significant statistical significant differences were found between the two study groups regarding age and gender.

In patients with Gilbert's syndrome, bilirubin levels showed substantial decrease over the 20-week follow-up, with more decrease after 10 weeks compared with the basal level ( $p$ value $<0.001$ ). Meanwhile, aspartate aminotransferase (AST), alanine transaminase (ALT) and $\gamma$-glutamyl transpeptidase (GGT) levels over the 20-week follow-up did not vary significantly; $p$ values $0.37,0.77$ and 0.46 , respectively (table 1 ).

In control patients, bilirubin and ALT levels did not vary significantly over the 20-week follow-up; $p$ value 0.23 and 0.28, respectively. Meanwhile, AST and GGT varied significantly over the 20-week follow-up; p value 0.018 and 0.002 , respectively (table 1 ).

Table 1 Follow-up and comparative study of liver function tests in controls and patients with Gilbert's syndrome treated with isotretinoin

\begin{tabular}{|c|c|c|c|}
\hline Case/variable & Gilbert's syndrome & Control & p Value* \\
\hline Basal bilirubin levels & $1.78 \pm 0.65$ & $0.50 \pm 0.22$ & $<0.001$ \\
\hline Bilirubin levels after 10 weeks & $1.03 \pm 0.18$ & $0.52 \pm 0.27$ & $<0.001$ \\
\hline Bilirubin levels after 20 weeks & $1.38 \pm 0.54$ & $0.48 \pm 0.26$ & $<0.001$ \\
\hline Basal AST levels & $22.1 \pm 5.1$ & $21.6 \pm 14.7$ & 0.14 \\
\hline AST levels after 10 weeks & $23.8 \pm 5.4$ & $21.4 \pm 7.8$ & 0.11 \\
\hline AST levels after 20 weeks & $21.5 \pm 7.1$ & $21.4 \pm 7.6$ & 0.95 \\
\hline Basal ALT levels & $20 \pm 10.4$ & $15.4 \pm 9.0$ & 0.12 \\
\hline ALT levels after 10 weeks & $21.1 \pm 7.9$ & $15.8 \pm 6.6$ & $<0.05$ \\
\hline ALT levels after 20 weeks & $18.2 \pm 7.3$ & $15.5 \pm 6.4$ & 0.25 \\
\hline Basal GGT levels & $18.1 \pm 9.9$ & $14 \pm 4.7$ & 0.35 \\
\hline GGT levels after 10 weeks & $24 \pm 1.7$ & $17.1 \pm 7.9$ & 0.23 \\
\hline GGT levels after 20 weeks & $17.1 \pm 4.5$ & $18.4 \pm 8.5$ & 0.79 \\
\hline
\end{tabular}


Table 2 Follow-up and comparative study of lipid profile in controls and patients with Gilbert's syndrome treated with isotretinoin

\begin{tabular}{|c|c|c|c|}
\hline Case/variable & Gilbert's syndrome & Control & p Value* \\
\hline Basal cholesterol levels & $143.6 \pm 19.5$ & $155.6 \pm 24.7$ & 0.09 \\
\hline Cholesterol levels after 10 weeks & $164.4 \pm 23.4$ & $176.3 \pm 30$ & 0.32 \\
\hline Cholesterol levels after 20 weeks & $162.7 \pm 12.4$ & $181.6 \pm 30.5$ & 0.11 \\
\hline Basal triglycerides levels & $71.2 \pm 27.2$ & $72.1 \pm 43$ & 0.54 \\
\hline Triglycerides levels after 10 weeks & $84.3 \pm 50.7$ & $93.5 \pm 46.4$ & 0.27 \\
\hline Triglycerides levels after 20 weeks & $67.2 \pm 31$ & $103.8 \pm 56.9$ & $<0.05$ \\
\hline Basal HDL levels & $53.5 \pm 15.2$ & $56.7 \pm 11.4$ & 0.33 \\
\hline HDL levels after 10 weeks & $53.5 \pm 14.8$ & $56.7 \pm 12.8$ & 0.46 \\
\hline HDL levels after 20 weeks & $62.4 \pm 17.5$ & $54.8 \pm 13.6$ & 0.23 \\
\hline Basal LDL levels & $78.1 \pm 13.9$ & $82.3 \pm 20.5$ & 0.54 \\
\hline LDL levels after 10 weeks & $95.3 \pm 19$ & $99.4 \pm 25.6$ & 0.71 \\
\hline LDL levels after 20 weeks & $88.3 \pm 14.1$ & $107.3 \pm 24.5$ & $<0.05$ \\
\hline
\end{tabular}

In patients with Gilbert's syndrome, LDL levels showed substantial increase over the 20-week follow-up, with more increase after 10 weeks compared with the basal level ( $p$ value $<0.001$ ). Meanwhile, cholesterol, triglycerides and high-density lipoprotein (HDL) levels over the 20- week follow-up did not vary significantly; $\mathrm{p}$ values $0.18,0.65$ and 0.32 , respectively (table 2 ).

In control patients, cholesterol, triglycerides and lowdensity lipoprotein (LDL) levels showed substantial increase over the 20-week follow-up; p value $<0.001$. Meanwhile, HDL levels over the 20- week follow-up did not vary significantly; $\mathrm{p}$ value 0.34 (table 2 ).

\section{DISCUSSION}

The main objective of the current follow-up study was to evaluate the hepatotoxicity of isotretinoin in patients with Gilbert's syndrome. In theory, hepatotoxic drugs such as isotretinoin would increase bilirubin and liver enzyme levels in patients with hereditary hepatic disorders such as Gilbert's syndrome. ${ }^{4}$

Before reaching conclusions based on the present results, it is necessary to consider a number of potential objections to the methodology. Limitations such as the small sample size could affect the validity of the results. Our study included only 37 patients with severe acne and treated with oral isotretinoin. It was difficult to identify more patients according to our strict inclusion and exclusion criteria, and that is why we included all patients treated over 4 years in three regional hospitals. Other possible limitations were the placebo effect and the natural evolution. Placebo effect was avoided by repeated measures; before treatment, and 10 and 20 weeks after treatment. Natural evolution was controlled by the follow-up comparative control group without Gilbert's syndrome. Although these results pertain solely to a region of the province of Jaén (Spain) and should not be considered generalisable, the methodology can be applied in different dermatology outpatient clinics. Our results call for further investigation of hepatotoxicity of isotretinoin in patients with acne and Gilbert's syndrome; future studies preferably should be performed on large prospective cohorts, to increase their internal validity.

By 10 weeks all patients with Gilbert's syndrome had a significant decrease in total bilirubin levels and they maintained this decrease after 20 weeks.

The cause for decline in bilirubin levels in patients with Gilbert's syndrome treated with isotretinoin is still unknown. Only few studies were published about this unexpected decline in bilirubin levels by a hepatotoxic drug like isotretinoin. ${ }^{9-11}$

Several drugs such as phenobarbitals and corticosteroids induce microsomal enzymes as uridine diphosphate glucuronyltransferase (UDP-GT) and stimulate the conjugation of bilirubin causing its decline. On the contrary, isotretinoin inhibits the inducer effect of other drugs and thus this does not seems to be its mechanism of action in patients with Gilbert's syndrome. ${ }^{12} 13$

Currently, there are two hypotheses to explain this unexpected effect of isotretinoin in patients with Gilbert's syndrome; reversible decrease in the serum levels of testosterone increasing the activity of UDP-GT or stimulating hepatocytes to generate transporting proteins that eliminate bilirubin. ${ }^{1415}$

None of the control group patients had significant increase in total bilirubin levels after 10 and 20 weeks of follow-up. It is of note that liver enzymes (AST, ALT and GGT) were maintained within normal levels in both study groups.

Our study also explored the adverse effect of isotretinoin on lipid profile levels. Both study groups did not show significant pathological increase in lipid profile levels (cholesterol, triglycerides, HDL and LDL). All lipid profile levels in patients with Gilbert's syndrome and control patients were maintained within the normal recommended levels. Recent follow-up study with 248 patients treated with isotretinoin because of acne vulgaris showed that only $1.2 \%$ suffered impaired LFTs and $1.61 \%$ had 
high-lipid profile levels after 16 weeks of treatment. ${ }^{16}$ These findings agree with our results after 10 and 20 weeks of follow-up in patients with Gilbert's syndrome and control patients.

LDL levels were increased in the two study groups, but this increase was less substantial in patients with Gilbert's syndrome. Again, these findings are contradictory to what would be expected from hepatotoxic drug administrated in patients with hepatic dysfunction.

Previous studies showed that patients with Gilbert's syndrome have lower prevalence of atherosclerosis and ischaemic heart disease. ${ }^{17} 18$ A systematic review confirmed that there is a reliable inverse and dose-response relationship between serum bilirubin and the atherosclerotic process. ${ }^{19}$ Recent case-control study showed that LDL, a well-known mediator of initial stages of atherosclerosis, was lower in patients with Gilbert's syndrome when compared with healthy controls. ${ }^{20}$ This agrees with the results of our study where basal levels of LDL and after isotretinoin treatment were lower in patients with Gilbert's syndrome compared with control patients.

In conclusion, our preliminary results suggest that oral isotretinoin is not only an effective safe treatment for patients with Gilbert's syndrome, but also it lowers bilirubin levels in the first 10 weeks of treatment. Identification of the mechanism of action of oral isotretinoin in patients with Gilbert's syndrome could help in elaborating new protective drugs against hepatotoxicity.

Contributors PF-C and JLC-F were involved in fieldwork supervision, analysis strategy and design, data management, data analysis and interpretation of results, decision-making on content and paper write-up and revision of final draft. MFA was involved in data analysis, interpretation of results, decisionmaking on content and paper write-up and revision of final draft. RF-CN was involved in study design, field work supervision, data analysis, decision-making on content and paper write-up and revision of final draft.

Funding This research received no specific grant from any funding agency in the public, commercial or not-for-profit sectors.

Competing interests None.

Patient consent Obtained.

Ethics approval Study approved by the Ethical Committee of Hospital de Andjúar.

Provenance and peer review Not commissioned; externally peer reviewed.

Data sharing statement No additional data are available.

Open Access This is an Open Access article distributed in accordance with the Creative Commons Attribution Non Commercial (CC BY-NC 3.0) license, which permits others to distribute, remix, adapt, build upon this work noncommercially, and license their derivative works on different terms, provided the original work is properly cited and the use is non-commercial. See: http:// creativecommons.org/licenses/by-nc/3.0/

\section{REFERENCES}

1. Marsden JR, Trinick TR, Laker MF, et al. Effects of isotretinoin on serum lipids and lipoproteins, liver and thyroid function. Clin Chim Acta 1984;143:243-51.

2. Vieria AS, Bejamini $\mathrm{V}$, Melchiors AC. The effect of isotretinoin on triglycerides and liver aminotransferases. An Bras Dermatol 2012;87:382-7.

3. Schmitt JV, Tavares M, Cerci FB. Adult women with acne have a higher risk of elevated triglyceride levels with the use of oral isotretinoin. [Article in English, Portuguese]. An Bras Dermatol 2011;86:807-10.

4. Gilbert syndrome. American Liver Foundation website. http://www. liverfoundation.org/abouttheliver/info/gilbertsyndrome/ (accessed 25 Jun 2013).

5. Dicken CH. Retinoids: a review. J Am Acad Dernatol 1984;11(4 Pt 1):541-52.

6. Grønhøj Larsen F, Jakobsen P, Grønhøj Larsen C, et al. The metabolism and pharmacokinetics of isotretinoin in patients with acne and rosacea are not influenced by ethanol. Br J Dermatol 2009;161:664-70

7. Meloche S, Besner JG. Metabolism of isotretinoin. Biliary excretion of isotretinoin glucuronide in the rat. Drug Metab Dispos 1986;14:246-9.

8. Nast A, Dréno B, Bettoli V, et al. European evidence-based (S3) guidelines for the treatment of acne. J Eur Acad Dermatol Venereol 2012;26(Suppl 1):1-29.

9. Wang JI, Jackson TL Jr, Kaplan DL. Isotretinoin-associated normalization of hyperbilirubinemia in patients with Gilbert's syndrome. J Am Acad Dermatol 1995;32:136-8.

10. Le Gal FA, Pauwels C. Gilbert disease and isotretinoin. Ann Dermatol Venereol 1997;124:463-6.

11. Black M, Sherlock S. Treatment of Gilbert's syndrome with phenobarbitone. Lancet 1970;1:1359-61.

12. Shah IA, Whiting $P H$, Omar G, et al. The effects of retinoids and terbinafine on the human hepatic microsomal metabolism of cyclosporin. Br J Dermatol 1993;129:395-8.

13. Rademaker $M$, Wallace $M$, Cunliffe $W$, et al. Isotretinoin treatment alters steroid metabolism in women with acne. $\mathrm{Br} J$ Dermatol 1991;124:361-4.

14. Goodman DS. Vitamin A and retinoids in health and disease. N Eng J Med 1984;310:1023-31.

15. Bruno NP, Beacham BE, Burnett JW. Adverse effects of isotretinoin therapy. Cutis 1984;33:484-6.

16. Muhammad Tahir Ch. Efficacy and adverse effects of systemic isotretinoin therapy. J Pak Assoc Dermatol 2011;21:38-42.

17. Vitek L, Jirsa M, Brodanova M, et al. Gilbert syndrome and ischemic heart disease: a protective effect of elevated bilirubin levels. Atherosclerosis 2002;160:449-56.

18. Schwertner HA. Bilirubin concentration, UGT1A1*28 polymorphism, and coronary artery disease. Clin Chem 2003;49:1039-40.

19. Novotny L, Vitek L. Inverse relationship between serum bilirubin and atherosclerosis in men: a meta-analysis of published studies. Exp Biol Med (Maywood) 2003;228:568-71.

20. Tapan S, Karadurmus N, Dogru T, et al. Decreased small dense LDL levels in Gilbert's syndrome. Clin Biochme 2011;44:300-3. 